\title{
TENDENCIAS DEL CONSTITUCIONALISMO EN EL SIGLO XXI: CUESTIONAMIENTOS E INNOVACIONES CONSTITUCIONALES
}

\author{
ANTONIO COLOMER VIADEL \\ Catedrático de Derecho Constitucional (j) \\ Universidad Politécnica de Valencia
}

SUMARIO

I. Introducción.

II. Cuestiones e innovaciones constitucionales.

\section{INTRODUCCIÓN}

El 14 y el 15 de septiembre de 1984 se reunía en Túnez la Asamblea de fundadores de la Academia Internacional de Derecho Constitucional. En aquella ocasión, y a semejanza de la Academia de Derecho Internacional de La Haya, constitucionalistas de todo el mundo nos propusimos crear esta Academia como un lugar de encuentro e intercambio de ideas en donde participaban académicos europeos, africanos, asiáticos y americanos.

El ambiente fue cordial aunque a la hora de elaborar la Proclama fundacional algunas tensiones se manifestaron entre ciertos representantes anglosajones - que pretendían identificar el modelo constitucional con la economía de mercado y la estructura social y política propia de los países occidentales-, y el único académico procedente de la URSS.

En la Asamblea participaba el profesor Boris Topornin, Director del Instituto del Estado y el Derecho Constitucional de la Academia de Ciencias de la URSS, que reivindicaba la identidad constitucional del Estado socialista.

En consecuencia hubo que llegar a un consenso que mantuviera integrados a todos los participantes fundadores y de ahí que bajo el título de la Academia quedara grabado un lema bien significativo: «La seule doctrine de l'Académie est d'être ouverte a toutes les doctrines». 
En el texto de la Proclama o declaración fundacional se señala que los miembros fundadores de la Academia constatan la tendencia marcada por todos los países a distinguir en el conjunto de las reglas jurídicas aplicables un cierto número de disposiciones que se imponen a todas las autoridades constituidas, incluidas las legislativas. Así se desprende un tipo de reglas llamadas a una particular estabilidad.

Las manifestaciones de esa tendencia general — continúa la Proclama- revisten formas diversas en los diferentes países, según contextos ideológicos, históricos y culturales variables, pero implican también problemas comunes.

En el párrafo siguiente se añade: «La interdependencia creciente de las naciones, y la necesidad de un mejor conocimiento común recomienda que estudiantes, investigadores y actores de diferentes países puedan conocer mejor las realidades contemporáneas en este dominio y reflexionar sobre su sentido, así como sobre sus posibilidades de evolución».

Este texto permitía integrar, ciertamente, a modelos constitucionales muy diferentes e incluso contradictorios a partir de la formalidad de la denominación constitucional y sobre el soporte del concepto de supremacía de la Constitución. En consecuencia, pudieron ponerse en marcha los cursos de la Academia sin que se produjera ninguna renuncia en el acuerdo fundacional.

Con la perspectiva del tiempo ahora vemos que cinco años después iba a caer el muro de Berlín y que siete años más tarde, en 1991, se produciría la desintegración constitucional de la Unión Soviética.

La bipolaridad antagónica se resquebrajaba y en apariencia íbamos hacia un mundo multipolar, pero con una pretendida hegemonía geoestratégica y cultural de los Estados Unidos, en donde se proclamaba el fin de la historia al culminarse un sistema que combinaba el modelo constitucional típico de los regímenes políticos occidentales, sea en su variante presidencial o en la parlamentaria, combinado con la economía de mercado de carácter capitalista.

Ciertamente en este comienzo del siglo XXI, precursor de nuevas búsquedas de organización del Estado y de articulación de la vida política bajo el prisma de esa globalización que llega hasta los últimos rincones del planeta, empiezan a bullir ideas y propuestas que revisan ese carácter monolítico del final de la historia.

La ideología de los Derechos Humanos y su universalización, la generalización de la democracia y su identificación con la estructura constitucional, van a ser las coordenadas fundamentales de esta evolución.

La propia doctrina de Naciones Unidas va a sufrir una mutación radical y el principio de no intervención en los asuntos internos salta por los aires bajo el pretexto de protección de los Derechos Humanos incluso contra la voluntad de los Estados en relación con sus propios ciudadanos.

«El destino manifiesto» de la potencia hegemónica del norte para exportar este modelo constitucional democrático tradicional íntimamente vinculado al modelo económico de economía de mercado capitalista, se va a exacerbar cuando 
esa intervención planetaria, para imponer el modelo único, se convierte también en una función de policía universal que se expresa, entre otros actos, en el nuevo concepto estratégico de la OTAN, aprobado el 24 de abril de 1999 en Washington, según el cual esta organización que respondía a un Tratado defensivo y delimitado geográficamente al espacio del Atlántico norte, descubre nuevos riesgos para la paz y estabilidad euroatlántica en conflictos étnicos, políticas de opresión, marasmo económico, colapso de orden político, en zonas periféricas a su espacio territorial. En suma, se descubre en ese nuevo concepto estratégico un enfoque global de seguridad por el que le afectan todos los peligros de actos de terrorismo, sabotaje, o delincuencia organizada. Y para ello las fuerzas de la Alianza que pueden verse obligadas a operar fuera de las fronteras de la OTAN, deben disponer de medios aptos para apoyar operaciones prolongadas ${ }^{1}$.

El atentado terrorista a las torres gemelas de Nueva York, en el 2001, va a llevar hasta el paroxismo esta función de policía universal y a poner la seguridad nacional por encima de las garantías de los derechos fundamentales, aplicando una especie de «estado de peligrosidad» sobre países y regiones enteras sospechosas de ser nichos que alberguen a los agentes de ese nuevo terrorismo internacional. Un ejemplo paradigmático de esta evolución ha sido la presencia, desde hace ya algunos años, de la OTAN, en Afganistán, aunque sea bajo una tenue cobertura de la ONU. Todo este proceso va a estar traspasado de consecuencias constitucionales y también de búsqueda de caminos constitucionales de evolución y salida.

En el caso de los Derechos Humanos y sus garantías, junto a los derechos individuales de libertad clásicos se suman los derechos sociales y laborales y las obligadas prestaciones de los Estados para hacerlos efectivos. Además, se suman los llamados derechos de tercera generación sobre la paz, el desarrollo y el medioambiente. Este último ha convertido a la bandera ecologista en una de las más universalizadas ante el temor de daño al planeta, por todos los abusos que los comportamientos económicos y sociales incontrolados están provocando.

El derecho al desarrollo es la expresión de la lucha por cerrar esa brecha de desequilibrios entre el norte y el sur, entre el desarrollo avanzado y el subdesarrollo excluido y marginal ${ }^{2}$.

La paz sigue siendo reivindicación compartida por culturas y civilizaciones, por pueblos y sociedades, en medio de una violencia tan amplia y extendida, no sólo por los conflictos bélicos sino por la desintegración social en donde organizaciones criminales y mafiosas ocupan el vacío que Estados fallidos o

1 Colomer Viadel, Antonio (coord.), El nuevo orden jurídico internacional y la solución de conflictos, Centro de Estudios Políticos y Constitucionales, Madrid, 2000, p. 8.

2 Colomer Viadel, A., "El Derecho fundamental al Desarrollo y su dimensión solidaria y comunitaria», en

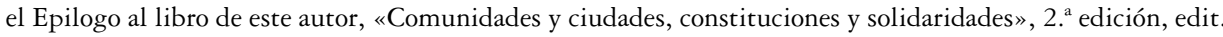
Ciudad Nueva, Buenos Aires, 2015, pp. 233-246. 
incompetentes no cubren para garantizar la seguridad jurídica y la paz social de sus ciudadanos ${ }^{3}$.

En medio de esta situación el concepto de soberanía nacional se debilita ante el poder de las organizaciones internacionales, económicas y comerciales, y de las alianzas militares y los acuerdos regionales. A veces podría pensarse que, por una parte, no hay reglas internacionales efectivas para regular las relaciones entre los Estados o los comportamientos ilícitos de mayor gravedad, mediante normas de Derecho Penal universal, y por otra, que la soberanía nacional aún sería un valladar contra intromisiones inadmisibles de grandes potencias y organizaciones en pequeñas sociedades nacionales.

Hay un clamor universal por una democracia que no sea meramente formal y limitada al derecho de sufragio, sino mediante una participación más intensa y cotidiana de los ciudadanos, así como por frenar la lejanía del poder mediante una desconcentración del mismo que vuelva a fortalecer municipios y regiones, sin desconocer el riesgo de los caciquismos locales.

Este panorama, ciertamente complejo y un tanto confuso, hizo saltar por los aires el mito del fin de la historia cuando también factores religiosos y distintos fanatismos pretenden regir la organización política de las sociedades y los Estados y deja abierta la reflexión, a los inicios del siglo XxI, sobre qué respuestas constitucionales pueden darse ante tantas angustias y demandas de los pueblos y sobre si el constitucionalismo realmente está capacitado para encontrar estas soluciones más allá de establecer unas reglas del juego claras y precisas que sean aceptadas por todos y nos den la seguridad de que no habrá trampas ni expolios en el seno de la comunidad política.

\section{CUESTIONES E INNOVACIONES CONSTITUCIONALES}

«Existen, sin lugar a dudas, unas condiciones mínimas institucionales y de principios para poder afirmar que nos encontramos ante un fenómeno constitucional. En primer lugar, el principio de supremacía de la Constitución sobre el que se basa el principio de legalidad y que tiene consecuencias fundamentales sobre la legitimidad política y para justificar la desobediencia civil, la resistencia a la opresión e incluso la revolución. En segundo lugar, los cauces para acceso a las magistraturas y órganos de poder que deben estar regulados en la Constitución. En tercer lugar, los mecanismos de responsabilidad de las autoridades como consecuencia de su sometimiento a la Ley fundamental. En cuarto lugar, los derechos y libertades de los ciudadanos y las garantías de los mismos. En quinto lugar, las instituciones de solución de conflictos: es decir, la regulación del pro-

3 Colomer Viadel, A. (coord.), «Cultura de Paz y medidas para Garantizarlas». Ed. Nomos, Valencia, 2001. 
ceso jurisdiccional para resolver los litigios. En sexto lugar, los procedimientos de reforma y defensa constitucional que condicionen a los órganos constituidos. Y por último, la fuerza de exigencia y aplicación de las propias normas constitucionales, ya que de no ser así, serían meras declaraciones programáticas» ${ }^{4}$.

Algún otro autor no considera suficiente afirmar que el constitucionalismo se articula en torno a cinco pilares (la Constitución escrita, el poder constituyente, la declaración de derechos, la separación de poderes y el control jurisdiccional de la constitucionalidad), ya que le parece necesario añadir que el constitucionalismo implica un planteamiento metodológico siempre dirigido a reforzar el límite del poder para evitar las arbitrariedades ${ }^{5}$.

Sin lugar a dudas esta limitación del poder por el derecho es importante, pero en sí misma no sería más que un aparato de ingeniería jurídica si no tuviéramos en cuenta el sentido finalista del ejercicio del poder y los valores que se buscan proteger y potenciar en la comunidad. La interpretación axiológica del constitucionalismo ha dado también lugar a polémicas y el propio autor citado apunta en su artículo los riesgos de la interpretación axiológica de la Constitución.

Parece, sin embargo, indiscutible que el concepto de dignidad de la persona es sobre el que va a bascular la articulación de los derechos fundamentales y las obligaciones de los poderes públicos para que ellos sean fundamentos del orden político y de la paz social (Véase el artículo 10 de la Constitución Española de 1978).

Ahora bien, no se trata sólo de aquellos derechos individuales de libertad como valladares a la intromisión del Estado en la vida de las personas sino la proyección solidaria del constitucionalismo que implica combinar las autonomías personales con la formas de crecimiento y desarrollo compartido que busquen la integración de la comunidad y el equilibrio entre sus elementos, a partir de la libertad y la igualdad de los mismos.

Todo ello está también vinculado a la importancia del concepto de soberanía popular y su proyección en las constituciones que necesariamente han de ser democráticas, pero también necesariamente han de ser solidarias, como escribí hace algún tiempo.

\section{Democracia}

«Constitucionalismo y democracia son inseparables, a partir de la construcción del concepto de soberanía popular, según el cual el pueblo es el soberano y de él emanan los poderes del Estado, y, en especial, ese poder constituyente como

4 Este párrafo está incluido en el capítulo introductorio titulado «Ideas sobre el origen y evolución del Constitucionalismo y su realidad contemporánea» en el libro de Colomer Viadel, Antonio Constitución, Estado y Democracia en el siglo XXI, UPV, Valencia, 2006, p. 37.

5 Pace, Alessandro, «Los retos del constitucionalismo en el siglo XXI», Revista española de Derecho Constitucional, n. ${ }^{\circ} 2$, julio-diciembre de 2004, pp. 172-173. 
poder extraordinario para constituirse del modo que mejor le convenga. De esta idea surge también el principio de solidaridad originaria por el que un fin primario es mantener la cohesión social y la integridad de la nación. Vinculado a lo dicho se encuentra el concepto de equilibrio que se ha manejado como concepto central para las relaciones entre los órganos y poderes del Estado, pero que resulta imprescindible, traspasado por los valores de igualdad y libertad, en las relaciones interpersonales e interciudadanas de los miembros de una comunidad. ¿Cómo pueden ser titulares de soberanía por igual ciudadanos en situaciones de radical desigualdad y hasta excluidos y discriminados algunos de ellos? Lo que debemos preguntarnos es si estos conceptos no pasan de ser un mito político, y, por tanto, una ficción jurídica o, a pesar de todas las dificultades, es un orden por construir vertebrado por los valores de justicia, solidaridad, libertad e igualdad $»^{6}$.

En este sentido, la solidaridad es fundamento de la constitucionalidad y no un simple principio reconocido. En consecuencia, en el Estado social y democrático de derecho hay que exigir la posibilidad de una equidad de oportunidades, que implica no sólo una igualdad ante la ley y un igual punto de partida legal sino una acción intensa de fomento del reequilibrio social ante situaciones de partida desiguales. Al lado de la democracia política debe construirse la democracia económica.

Estas primeras consideraciones nos llevan a revisar algunos de los conceptos que nos parecen indiscutibles como el de la democracia vinculada al Estado constitucional. Es evidente que la democracia no puede limitarse al simple derecho de sufragio por más que este sea fundamental siempre que se de en situaciones de información veraz a la opinión pública, transparencia publicitaria y pluralismo de opciones políticas. Ahora bien, los ciudadanos quieren intervenir con más frecuencia en las decisiones políticas que afectan a su vida cotidiana y a los asuntos que verdaderamente le preocupan. De ahí la necesidad de combinar la democracia representativa con formas de democracia participativa que revaloricen mecanismos de democracia directa como el referéndum, la iniciativa legislativa popular, la revocación de mandatos, etc. y también los procedimientos de diálogo y comunicación entre las sociedad civil y sus organizaciones y las administraciones públicas con la posibilidad de sorteos aleatorios entre los ciudadanos para estar presentes con mecanismos de control y observación en las diferentes entidades de poder y administración ${ }^{7}$.

6 Colomer Viadel, Antonio, Comunidades y ciudades, Constituciones y solidaridades 1 ra Edición, UPV, Valencia, 2007, pp. 29-30. Hay una 2. ${ }^{\text {a }}$ edición de esta obra ya citada en nota 2.

7 Lizcano Fernández, Francisco, «Dos géneros básicos del sistema político y dos especies básicas de democracia» en Colomer Viadel Antonio (coord.), Autogestión, Cooperación y Participación en las Ciencias Sociales, Ugarit, Valencia, 2009, pp. 65-74. Véase también de Francisco Lizcano «Compatibilidad entre democracia directa y democracia representativa», en Revista Iberoamericana de Autogestión y Acción Comunal n. ${ }^{\circ} 55$, otoño de 2009, INAUCO-UPV, pp. 103-129.

Asimismo, Colomer Viadel, Antonio (coord.), La participación en las administraciones públicas ¿cooperación o enfrentamiento?, UPV, Valencia, 2006. 
En contrapunto a esta demanda generalizada es cierto también que asistimos a los fenómenos de personalización del poder convirtiendo los liderazgos políticos en verdaderos caudillismos reforzados por el hipnotismo televisivo, como plataforma hegemónica de los dirigentes de los partidos políticos más poderosos.

Hace cerca de cuarenta años, al inicio de 1978 y escribiendo sobre el proyecto de la Constitución española que ese año se iba a aprobar, me lamentaba de que los constituyentes no hubieran esgrimido la imaginación necesaria para interiorizar constitucionalmente esos nuevos protagonistas sociales y políticos que la sociedad contemporánea estaba demandando, para salir de la falta de credibilidad en las instituciones. Citaba allí al famoso navegante y oceanógrafo Jacques Ives Cousteau que se hacía eco de una inquietud universal al decir: «Afirmar que los ciudadanos se sienten satisfechos de entregar, cada cuatro o cinco años, un mandato a un representante que no les representa más, no corresponde a nada en este mundo radicalmente transformado».

«La gente quiere tener una influencia real sobre su vida de cada día y no una vez cada cuatro o cinco años. Existe tal anacronismo entre el actual sistema y la realidad que una gran cólera está creciendo en el mundo. Los ciudadanos del mundo entero han dejado de creer en los sistemas políticos, se burlan y desconfían de sus dirigentes».

Precisamente treinta años después volví a recoger esta cita en un libro colectivo sobre «Regenerar la política». En el capítulo introductorio titulado «Algunas reflexiones sobre la regeneración democrática y la conciencia ciudadana» exponía algunas medidas jurídico-políticas transformadoras. La primera es la de tender a la no reelección de los cargos representativos, para permitir una mayor rotación en estos y también el recurso al sorteo aleatorio entre ciudadanos para el ejercicio de ciertas responsabilidades públicas. La segunda es la de descentralizar el poder y aplicar el principio de subsidiariedad, de tal forma que todo lo que se pueda hacer en las instancias más inmediatas a la ciudadanía no debe hacerse en un escalón superior. En este sentido señalaba hacia un municipalismo renovado de carácter integrador y de cooperación solidaria y no de localismos egoístas y aislados.

La tercera medida era la reivindicación de las instituciones de democracia directa y semidirecta y recurrir a ellas con más frecuencia y normalidad, para que el pueblo soberano pueda decir la última palabra en cuestiones de especial trascendencia. El ejemplo suizo es paradigmático.

En cuarto lugar reivindicaba el antiguo concepto del «poder negativo» o poder de impedir o controlar, cuyo origen está en la República romana y ejercido por el Tribuno de la Plebe. Ahora la institución del Defensor del pueblo, soporte de los ciudadanos frente a los abusos o negligencia de las administraciones, sería su mejor instrumento y extendido hasta los ámbitos locales. La elección popular de los mismos, la posibilidad de que puedan presentar recursos de inconstitucionalidad y también, con ciertas condiciones y garantías, promover la convocatoria de referéndum popular, reforzaría su papel de freno de los abusos del poder. 
La quinta medida propuesta es el giro hacia una teoría de la administración pública cooperativa que debe interiorizar prácticas de cooperación entre administradores y administrados, para que los ciudadanos con carácter rotatorio y temporal, a través de sus asociaciones o individualmente, por sorteo, estén presentes en los distintos órganos de la administración, puedan exponer sus sugerencias e iniciativas y también contemplar los problemas y dificultades de la gestión pública.

En sexto y último lugar, se propugna la existencia de jueces confiables que apliquen la Ley con equidad y respondan a esa triple I: Independencia, Imparcialidad e Integridad, que es necesaria y beneficiosa en un orden de justicia. También hay que potenciar y desarrollar la mediación, sea judicial o no, que busque resolver los conflictos propiciando una comunicación y entendimiento entre las partes, en donde todas ellas salgan beneficiadas y también todas hagan algunas renuncias o concesiones, sin caer en el resentimiento de la derrota o en el triunfalismo de la victoria ${ }^{8}$.

Desde un punto de vista constitucional asistimos en los últimos tiempos a la constitucionalización de los partidos políticos que se convierten en instrumentos fundamentales para la participación política y en el plano parlamentario, a través de la disciplina de los grupos parlamentarios, se ha reinventado un camuflado mandato imperativo de la obediencia debida que recuerda más a las excusas para cometer atrocidades de los regímenes totalitarios que a la conciencia de servicio a la nación de una democracia representativa, en la que, paradójicamente, sus textos constitucionales prohíben ese mandato imperativo, vestigio del Antiguo Régimen. Por ello se ha llegado a decir que vivimos un verdadero Estado democrático de partidos que tiende a monopolizar la manifestación de la voluntad popular y de la participación política dejando a los ciudadanos y sus organizaciones sociales prácticamente excluidos de esa formación de la voluntad popular?.

La situación de los partidos políticos y su engarce constitucional es muy heterogénea en el mundo. Existen países en donde la estructura de partidos es muy débil y ello impide tener interlocutores válidos en la vida política, a veces sustituidos por el peso de los clanes, tribus u otras organizaciones comunitarias. También se produce el fenómeno de los diputados individuales con el apoyo de pequeños grupos locales lo que lleva al gobierno a tener que negociar uno a uno con cada diputado y ofrecerles recompensas personales o para su grupo o territorio a cambio de obtener su apoyo parlamentario. Es el caso de Brasil y otros países latinoamericanos. En las constituciones de esta región se exige, en muchos casos, la vinculación a un partido político para poder ser candidato, lo que cierra la puerta a agrupaciones electorales de ciudadanos y a iniciativas de la sociedad civil en el campo electoral.

8 Colomer Viadel, Antonio (coord.), Regenerar la política, ciudadanos, ;sed protagonistas!, Ugarit, Valencia, 2008, pp. 17-28.

9 Torres del Moral, Antonio, Estado de Derecho y Democracia de partidos, Universidad Complutense de Madrid, 1991. 


\section{Eficacia del derecho, control de constitucionalidad y judicatura}

Otro reproche que podríamos hacer a nuestros textos constitucionales es el abuso de las normas programáticas que representan vagas intenciones de mejora colectiva o de etéreas expectativas de cambios sociales, pero sin fuerza jurídica positiva y pendientes de desarrollo legislativo posterior para ser aplicables y exigibles ante los jueces y los tribunales. El derecho debe tener una voluntad irrenunciable de efectividad y en consecuencia debiera desaparecer de la vigencia jurídica aquellas normas inaplicables o dejadas en ese limbo jurídico programático. Existen mecanismos tanto de criterios de analogía como de aplicación de tratados internacionales, así como la inconstitucionalidad por omisión o el mandado de injunçao, innovación imaginativa de la Constitución brasileña de 1988, aunque inaplicado por la resistencia de los jueces conservadores. Y, por descontado, las iniciativas populares para forzar esa efectividad de las normas programáticas o que los legisladores y políticos asuman la responsabilidad de borrarlas de las constituciones y las leyes constitucionales ${ }^{10}$.

En este campo es especialmente trascendente el control de constitucionalidad de las leyes y que la interpretación constitucional pueda realizarse de forma rigurosa y en ese papel básico de la jurisprudencia como garante de la Constitución y para controlar las acciones de los hombres — señala Christian Stack—, que no están al abrigo de errores, abusos y usurpaciones, sobre todo cuando están vinculados al poder. Para que esa primacía constitucional esté asegurada por el control judicial de las leyes, la claridad y precisión del derecho constitucional es una condición previa para el necesario reparto de competencias entre el Parlamento y la Corte Constitucional que va a controlar su actividad de acuerdo con la Constitución ${ }^{11}$.

En relación a este tema otra cuestión decisiva es la forma de reclutamiento de los miembros de los tribunales constitucionales, para garantizar su independencia, rigor e imparcialidad, e impedir las interferencias políticas y partidistas. Afinar estos mecanismos de elección es fundamental para una función constitucional tan decisiva como las que deben ejercer estas Cortes o Tribunales.

Ciertamente estas consideraciones podríamos extenderlas a la situación general de la judicatura. La independencia del poder judicial como premisa constitucional es aún indiscutible cuando el poder ejecutivo y el legislativo, especialmente en los sistemas parlamentarios, tienden no sólo a una colaboración de poderes sino a un verdadero sometimiento de la mayoría parlamentaria, a la cabeza de esa mayoría representada por el gobierno.

10 Colomer Viadel, Antonio, «Las normas constitucionales de carácter programático y los procedimientos para conseguir su eficacia» en el libro del autor Constitución, Estado y Democracia en el siglo XXI, op. cit., pp. 63-84.

11 Stack, Christian, «La Suprématie de la Constitution», Recueil des Cours de L'Académie Internationale de Droit Constitutionnel, Ed. Toubkal, Casablanca, 1987, p. 31 y ss. 
Las interferencias del ejecutivo e incluso de otros poderes sociales y económicos sobre la independencia judicial es uno de los problemas más graves para que se pueda garantizar la existencia de un verdadero Estado de derecho. En numerosos Estados constitucionales esa independencia no está asegurada y el tratamiento desigual de la judicatura a los ciudadanos, de acuerdo con juegos de intereses e influencias, es una penosa realidad. Abordar cambios radicales en la configuración del poder judicial es una exigencia inexorable de este siglo XXI.

\section{Derechos, libertad y garantías}

Aquella antigua alternativa entre libertades de los antiguos y libertades de los modernos que expuso a comienzos del siglo xix Benjamín Constant, que suponía la libertad de participación presente en el mundo griego clásico frente a la libertad de resistencia o de freno a la intervención del poder estatal, para el ejercicio sin trabas de los derechos individuales como los de libertad y propiedad, que era expresión para este autor de la modernidad y giraba en torno a la libertad de pensamiento y de expresión y a la libertad económica y comercial, pareciera ahora haberse invertido y volver a los orígenes.

Nos encontramos en el tiempo de los derechos, como decíamos en la introducción, y las obligaciones constitucionales han consagrado y universalizado esa protección de los derechos humanos como derechos fundamentales. En el orden clásico jurídico un derecho subjetivo implica establecer a favor de quien se reconoce, es decir, quién es el sujeto activo titular; contra quién resulta oponible o sea el sujeto pasivo; cuál es la obligación que grava al sujeto pasivo: de omitir, de dar o de hacer, y cuál es la vía de ejecución del derecho ${ }^{12}$.

La emergencia de los derechos sociales, laborales y económicos ha llevado implícita las obligaciones del Estado para realizar las prestaciones necesarias que hagan efectivos estos derechos. Hay una evolución desde los derechos individuales hacia derechos de grupos sociales. Al mismo tiempo la intervención creciente del Estado en el horizonte más o menos utópico del Estado de bienestar, implica un cierto riesgo para las libertades individuales, mediante mecanismos de interferencia como la expropiación forzosa o el uso social de la propiedad. En todo caso, ello nos ha llevado en el constitucionalismo contemporáneo a la aparición de una verdadera «Constitución económica», con cierta autonomía y entidad propia en el marco de los textos constitucionales.

En este campo de los derechos un fenómeno también de estos últimos tiempos es la relevancia de los derechos de las minorías, el derecho a la diferencia y a la identidad propia junto al pluralismo jurídico y cultural enmarcado por las reglas de juego constitucionales.

12 Bidart Campos, Germán, Constitución y Derechos Humanos, Ediar, Buenos Aires, 1991, p. 61. 
Es interesante observar en las constituciones latinoamericanas de países con población indígena significativa el reconocimiento de la coexistencia entre el derecho estatal y el derecho consuetudinario indígena y la ponderación por las Cortes Constitucionales de ambos derechos e incluso de algunas jurisdicciones autónomas de estas comunidades étnicas en la aplicación de sus reglas de derecho propias $^{13}$.

La polémica entre monismo y pluralismo jurídico está abierta y viva, pero enriquece el mundo de los derechos el reconocimiento de esa pluralidad siempre que haya un respeto a los contenidos esenciales de los derechos fundamentales.

Otra cuestión es la relación entre derechos, deberes y responsabilidades. La exacerbación del reclamo de derechos ha debilitado la conciencia de los deberes, aunque en los últimos años hay un resorte ético, a través de las formas del voluntariado y las organizaciones solidarias, que atisba un renacer de la conciencia de las responsabilidades y el fortalecimiento del principio de reciprocidad que debe tener también un reflejo constitucional.

Por último señalar la importancia del sistema de garantías que nos asegure la efectividad de los derechos y la posibilidad de reclamar en caso de violación o desconocimiento de alguno de ellos. Ya hicimos referencia a la garantía institucional del Defensor del Pueblo. También la generalización del amparo constitucional, sea ante jueces ordinarios o ante tribunales constitucionales.

La impregnación del conjunto de las disposiciones constitucionales por el sistema de derechos fundamentales, hace que casi cualquier norma afecte a uno de ellos y en consecuencia tenga las garantías de reserva de Ley o de Ley orgánica, en casi todas las materias. El sistema garantista es una preocupación fundamental de la arquitectura constitucional hasta el punto de que hay países, como México, que regulan un sistema de garantías dando por supuesto implícitamente la declaración de derechos.

Las facilidades a la iniciativa ciudadana para recurrir en amparo o quejarse ante los defensores del pueblo u Ombudsman conectan al sistema de garantías con el principio de participación ciudadana en las democracias constitucionales y favorece la efectividad de estas garantías.

Evidentemente no podemos desconocer la existencia de las constituciones nominales o semánticas que se quedan, en esta materia, y también en la organización del poder, en meras proclamas retóricas que no responden a la realidad.

Parece evidente que en el constitucionalismo post industrial junto a la estructura social que favorece la universalización de la economía de mercado libre, y la estructura política que busca nuevos controles y formas de participación, la estructura cultural se traduce en el «Derecho a tener derechos», los derechos de

13 Cabedo Mallol, Vicente, Constitucionalismo y Derecho Indígena en América Latina, UPV, Valencia, 2004. 
la tercera generación —al ambiente, al desarrollo, a la paz-, y en el resguardo de la diferencia ${ }^{14}$.

El clamor en el siglo XXI por el cambio climático y la protección medioambiental se convierte en una expectativa de los pueblos que quisiera traducirse en derechos subjetivos. En algunas legislaciones penales se ha introducido el delito ecológico por el daño al medioambiente. Nos encontramos ante una gran expectativa colectiva de salvaguardia planetaria que también tendrá que tener un eco constitucional.

No podemos olvidar en esta materia la protección supranacional de los derechos mediante jurisdicciones y tribunales que obligan a los jueces y tribunales nacionales, al haberse suscrito por los Estados convenios internacionales de protección de los derechos. Queda así la posibilidad de una última instancia a la que se someten los Estados donde incluso sus nacionales pueden recurrir en defensa de sus derechos. El Tribunal Europeo de Derechos Humanos, con sede en Estrasburgo, Francia, es un ejemplo notable con sentencias condenatorias de distintos Estados europeos por recursos de sus ciudadanos. La Corte Interamericana de Derechos Humanos puede ser potenciada y su jurisdicción, sin lugar a dudas, tendría una influencia sobre los jueces nacionales ante el temor de que sentencias inadecuadas puedan ser recurridas y desmontadas.

El reconocimiento de los tratados en el orden jurídico interno, de acuerdo con las propias constituciones y con un régimen especial de protección, es una garantía reforzada de los derechos que hay que señalar como un signo positivo del siglo XXI, por más que aún no tenga la universalidad que sería deseable.

\section{Regímenes políticos: presidencialismo y parlamentarismo}

Las dos formas predominantes del estatuto del poder en las constituciones actuales son el régimen presidencial y el parlamentario. El principio mítico de la división de poderes se mantiene a duras penas en el primero y ha sido desmontado en el segundo por una forma de colaboración de poderes que supone - como ya dijimos - un verdadero sometimiento de las mayorías parlamentarias a la dirección de los gobiernos que son cabeza de esas mayorías.

El modelo presidencial norteamericano mantiene aún cierto equilibrio entre la institución presidencial y el Congreso, pero las múltiples formas de reforzamiento de la presidencia por su liderazgo democrático y la jefatura de las fuerzas armadas de una potencia con una presencia internacional tan intensa, permite al presidente operar con autonomía a través de diferentes procedimientos ejecutivos sin necesidad de una explícita autorización del legislativo. El consenso sobre el liderazgo político de la presidencia como referente nacional hace que, incluso con

14 Frías, Pedro J., «El constitucionalismo actual», en Revista chilena de Derecho, vol. 19, n. ${ }^{\circ}$ 1, p. 54, 1992. El profesor argentino cita estas estructuras señaladas por Daniel Bell. 
resistencias para aprobar algunas leyes, se respete la iniciativa presidencial en la mayoría de los casos.

El régimen presidencial en los países iberoamericanos tiene diferencias considerables con el modelo norteamericano. El papel histórico de la presidencia en aquellas repúblicas, cuando la estructura social era muy débil y tuvo que realizarse un sobreesfuerzo de integración nacional, fortaleció a esta institución hasta la aparición del fenómeno del presidencialismo, en superlativo. El predominio constitucional de los presidentes de la república tiene su reflejo en facultades presidenciales recogidas en la Constitución que, en algunos casos, llegan a la concesión de amplias delegaciones legislativas, pero también a prácticas políticas que han llevado a una tipología que establecí en cuatro modelos:

1. Presidencialismo hegemónico de excepción. En este caso se produce una invasión absoluta de las esferas de competencias de los otros poderes por el ejecutivo, de manera temporal, o existe la posibilidad permanente de recurrir a procedimientos de excepción para atribuirse, de nuevo, competencias en numerosas materias y especialmente en las relacionadas con la libertad y la seguridad pública. Asimismo, existe una mediatización del ejecutivo presidencial en los nombramientos y la selección de miembros de los otros poderes. Los mecanismos del constitucionalismo de excepción son la herramienta para esta actuación.

2. Presidencialismo hegemónico constitucional democrático. En esta segunda categoría la hegemonía presidencial sobre los otros poderes no se realiza por mecanismos de excepción sino mediante el uso regular de las amplias facultades del ejecutivo, previstas en la Constitución. La reiterada delegación por los otros poderes de facultades extraordinarias al Presidente. También la influencia política de la presidencia en el reclutamiento de los miembros de los otros poderes es un factor de la hegemonía de la presidencia. El origen democrático del poder, el pluralismo limitado y la garantía relativa de libertades públicas lo distingue del anterior.

3. Presidencialismo autónomo de equilibrio de poderes. En este grupo la primacía presidencial es de carácter funcional debido al incremento del número e importancia de su actividad ejecutiva, propia del Estado interventor, y por el liderazgo político popular. La influencia sobre el legislativo es de carácter político fáctico, aunque se mantiene cierta apariencia de equilibrio de poderes.

4. Presidencialismo con sujeción parlamentaria. En esta categoría debemos incluir aquellos regímenes que han intentado una cierta parlamentarización del régimen presidencial mediante el carácter colegiado del gobierno, el nombramiento de un primer ministro, la posibilidad de interpelar y censurar a los ministros por el Congreso, el obligado refrendo ministerial a las decisiones del Presidente, la autorización parlamentaria para los viajes del Presidente o la posibilidad de un juicio parlamentario del Presidente. 
Todos estos mecanismos presidenciales han operado de forma irregular y no han acabado de disminuir el predominio presidencial en estos países ${ }^{15}$.

En cuanto a los regímenes parlamentarios ya señalamos la quiebra del principio de división de poderes y el fenómeno de personalización carismática del líder de la mayoría parlamentaría que normalmente asume la cabeza del Ejecutivo. Las elecciones parlamentarias se convierten así en plebiscitos electorales, a favor de un líder o de otro, aunque posteriormente el mecanismo de investidura haga que la jefatura de gobierno tenga que ser refrendada por la mayoría parlamentaria surgida de las elecciones.

Esta inversión de la relación de los poderes hace que el gobierno se convierta en el gran protagonista de las iniciativas legislativas y que difícilmente prosperen las enmiendas de la oposición parlamentaria y que tampoco tenga expectativa de éxito las formas más radicales de control parlamentario como son las mociones de censura. Todo ello ha provocado una desnaturalización del sentido originario de la vida parlamentaria, en donde, de una parte, el Parlamento era el gran creador de la legislación y por otra, ejercía un control férreo sobre el gobierno. ¿Qué es lo que nos queda? Nos queda reforzar el papel del Parlamento como el gran lugar de debates políticos públicos, que no es poco, si se dan en un sistema de transparencia y de publicidad y de confrontación libre de distintas opciones que tengan su reflejo, a su vez, en unos medios de comunicación de masas también libres y plurales.

La regulación reglamentaria de estos debates públicos, la presencia de las minorías en los órganos de gobierno parlamentario, la consideración de estas minorías en la elaboración de la Ley, la iniciativa para constituir comisiones de investigación, etc., puede convertir la mutación del órgano parlamentario en la hora actual en un ámbito de virtualidad democrática efectiva para ilustrar a la opinión pública y al cuerpo electoral y permitir la alternancia en el poder en las coyunturas de las elecciones futuras ${ }^{16}$.

Dado el fenómeno de mimetismo constitucional por el que los modelos de constituciones europeas y de la norteamericana han sido imitados en otras regiones de los distintos continentes no podemos desconocer que bajo una fórmula presidencial o parlamentaria se enmascaran relaciones de poder que no responden exactamente a estos mecanismos sino a la dinámica de grupos sociales de base étnica, religiosa, política, económica, militar, etc., que son los efectivos detentadores del poder, por más que luego asuman los hábitos de las magistraturas constitucionales. De ahí también la inestabilidad de estos sistemas constitucionales y regímenes políticos en donde unas camarillas sustituyen a otras de acuerdo, no con los cauces constitucionales, sino con el peso relativo de los grupos de apoyo y los intereses en juego.

15 Colomer Viadel, Antonio, Introducción al constitucionalismo iberoamericano, 2. ed. Trillas, México, 2009, pp. 134-150.

16 «El papel y las garantías de la oposición parlamentaria en Europa», capítulo III de la cuarta parte del libro Constitución, Estado y Democracia en el siglo XXI, op. cit., pp. 343-374. 


\section{Descentralización y estructura territorial del estado}

Otro reproche arraigado ha sido el de la lejanía del poder por el excesivo centralismo, lo que dificultaba la comunicación de las administraciones con los ciudadanos, impedía una fluida comunicación de éstos con sus representantes y hacía muy lento el proceso de toma de decisiones y la aplicación de las mismas.

Hemos asistido en los últimos tiempos a un reclamo generalizado para una amplia descentralización del poder y potenciación de los gobiernos locales mediante diferentes modalidades.

Una de las vías ha sido recobrar el sentido auténtico del federalismo que había quedado en muchos casos como forma residual, por la hegemonía del poder central. Ir a una fórmula de distribución de competencias más efectiva ha sido un objetivo de las reformas constitucionales en estos Estados federales en las últimas décadas del siglo $\mathrm{xx}$.

En los Estados unitarios se han planteado también procesos de regionalización, dando competencias a provincias o departamentos y recobrando la importancia del municipio, una institución con una tradición histórica de ejercicio de funciones próximas a la ciudadanía, a la vez que verdadera escuela de democracia.

Estas vías de desconcentración del poder y de descentralización territorial del Estado han adoptado distintas modalidades, pero, en todo caso, pareciera una finalidad constitucional indiscutible en la nueva organización de los Estados en el siglo $\mathrm{XXI}^{17}$.

En esta descentralización convendría tener presente las realidades culturales, étnicas y sociales vinculadas a territorios diferenciados, tan importantes en las comunidades africanas, también en países asiáticos y latinoamericanos. Un ejemplo interesante es el reconocimiento de autonomías indígenas en la Constitución de Bolivia de 2009. El problema es encontrar el punto de equilibrio entre la cohesión nacional de integración solidaria y el respeto diferencial a las identidades propias de estas autonomías. Lo que no siempre es fácil.

\section{La integración supranacional}

La globalización que vive el mundo en estos inicios del siglo XxI exige la presencia de protagonistas fuertes en el plano económico y cultural de este orbe mundial cada vez más hegemónico y vinculado.

La crisis y casi obsolescencia del concepto de soberanía nacional y también de otros, tal como la ley, expresión de la voluntad general, o la de la representación

17 Colomer Viadel, Antonio, «Federalismo y democracia», en Foro Nacional Hacia un Auténtico Federalismo, Guadalajara, México, 1995, pp. 97-103. Y del mismo autor «Ciudadanía y proximidad. El protagonismo de los ciudadanos» en Comunidades y ciudades, Constituciones y solidaridades, op. cit., pp. 135-144. 
política y parlamentaria, se vincula también al mito del protagonismo autónomo de los Estados nacionales y el poder supremo de su soberanía, como interlocución entre iguales en las relaciones internacionales.

Por otra parte, muchos Estados ya no pueden garantizar por sí solos la seguridad jurídica y la paz social de sus ciudadanos ni prestar aquellos servicios públicos sobre salud, enseñanza, vivienda, etc., que alcancen por igual a toda la ciudadanía. Hace tiempo escribí respecto a los países iberoamericanos que, con alguna excepción, solo alcanzaran a constituir el Estado de derecho en ellos mediante un posible proceso de integración regional supranacional.

Aunque parezca una paradoja puede combinarse y es complementaria la integración supranacional con la descentralización infranacional. Esta tendencia a constituir organizaciones de integración es cada vez más generalizada, con procesos ya con una buena andadura como el europeo, pero avances también en América, África y Asia. Este fenómeno nos exige plantearnos el derecho constitucional de la integración, en donde deben clarificarse las competencias transferidas a los organismos de integración, lo que supone limitar las competencias que retiene para sí el poder estatal y, sobre todo, fortalecer los cauces de crecimiento sinérgico y de protección reforzada a los derechos fundamentales y al apoyo mutuo social, económico, cultural, monetario. El desarrollo del derecho comunitario europeo es un buen ejemplo de limitación de las soberanías nacionales y de interiorización de estas reglas comunitarias en el orden jurídico interno de los Estados.

Algo parecido podríamos señalar y es aplicable al Mercosur y a otras organizaciones de integración regional en América Latina. Precisamente una de las claves de su éxito es tener reglas claras y precisas en el equilibrio señalado entre las competencias de integración y las estatales. También, por cierto, organismos eficientes para el funcionamiento de integración y todo ello tiene un impacto constitucional creciente que en algún momento llevará, al modo de las Constituciones federales, a la creación de Constituciones de las estructuras de integración de Estados $^{18}$.

Todas estas consideraciones no nos pueden hacer olvidar que la realidad mundial es la de un mundo ancho y ajeno y también complejo y, a menudo, contradictorio. Así, por ejemplo, no podemos desconocer que aunque la existencia de Constitución en los Estados es un fenómeno universal y que se identificaba con la mayoría de edad, tras la independencia de antiguas colonias y la incorporación a las Naciones Unidas, el mimetismo constitucional llevó a una pura reproducción de modelos occidentales que no respondían a las realidades sociales de las comunidades políticas en las que debían aplicarse tales constituciones. Ello ha dado lugar al tan frecuentemente citado fenómeno de constituciones semánticas o no-

18 Dromi San Martino, Laura, Derecho constitucional de la integración, Universidad Complutense de Madrid - editorial Argentina, Madrid, 2002.

Colomer Viadel, Antonio (coord.), La integración política en Europa y en América Latina, colección PO-DER, IBEM, Valencia, 2007. 
minales, de acuerdo con la clásica clasificación de Loewenstein, precisamente por el carácter puramente retórico de los textos que en muy poca medida regulaban las relaciones de poder reales en tales sociedades.

\section{Laicismo y religión}

Otro fenómeno a considerar es el de la influencia religiosa en los textos constitucionales frente al laicismo generalizado de las constituciones occidentales. En este sentido, los países musulmanes son básicamente confesionales y reconocen el Islam como la religión del Estado y ello tiene numerosas consecuencias políticas y sociales. Hay que recordar que el derecho musulmán se basa en la Sharia que tiene cuatro elementos; la revelación divina transmitida por Mahoma en el Corán; la Sunna, reglas extraídas por la labor de los intérpretes, de las palabras y acciones del profeta; la Idjma, reglas de consenso de la doctrina jurídica musulmana; y el Qiyas, conjunto de reglas extraídas por analogía de las normas de las otras fuentes. Todo este derecho jurisprudencial tuvo su origen del siglo viI al $\mathrm{x}$ y ciertamente es difícil adaptarlo a la realidad actual. De ahí que en algunos casos coexista el derecho divino y el derecho político, pero con el predominio del primero. Entre los países musulmanes hay algunos donde este equilibrio es mayor, como Túnez, Egipto, Irak, Siria y otros, donde claramente prevalece el derecho musulmán sobre el político: Libia, Irán, Arabia Saudita ${ }^{19}$.

Actualmente estoy dirigiendo la tesis doctoral del jurista jordano, Diaa Abu Fannas, sobre «Los derechos fundamentales, las libertades públicas y su sistema de protección en Egipto y Jordania: una reformulación crítica desde la experiencia constitucional española», en donde el autor se plantea la dificultad de la protección de esos derechos o porque no están regulados o porque son prácticamente inoperantes los mecanismos de garantía y, desde luego, los problemas de la influencia de la religión islámica en el ejercicio y protección de los derechos fundamentales y las libertades públicas.

El mundo árabe no está constituido por una realidad homogénea. Las evoluciones políticas, constitucionales, sociales y económicas de los distintos Estados integrados en esta realidad son muy dispares, más allá de que exista un pensamiento político panarabista instalado en parte de su ciudadanía, y más allá de la fe islámica, entendiendo ambos fenómenos como factores de cohesión y relativa homogeneidad. La Primavera Árabe, a pesar de las diferencias nacionales, respondió a un estallido causado por factores comunes. Los manifestantes, influenciados por la fuerza atractiva de los sistemas políticos instalados con firmeza en Europa y en otros lugares del mundo, exigieron un cambio político y constitucional que

19 López Garrido, Diego; Massó Garrote, Marcos Francisco; Pegoraro, Lucio (directores), Nuevo Derecho Constitucional Comparado, Tirant Lo Blanch, Valencia, 2000, p. 87 y ss. 
hiciera posible la eficaz realización política y jurídica de derechos fundamentales y libertades públicas, que pusiera fin a las arbitrariedades y corrupciones de los poderes públicos, y que instaurara unos regímenes políticos fundados en la participación ciudadana expresada con libertad y pluralismo político e ideológico. El movimiento de protesta social, como ocurre siempre en fenómenos de esta índole, también clamó por cambios económicos, que solo serían posibles mediante un gradual reconocimiento y plasmación constitucionales de derechos sociales, económicos y culturales con entidad suficiente como para plantear unas relaciones de producción y distribución de la riqueza más equitativas y eficaces. La injusticia económica derivada de unos regímenes políticos teñidos de corrupción ha impedido durante decenios el despegar económico de estos Estados, cercenando sus potencialidades de crecimiento y progreso.

Los procesos de transición de los países árabes no han culminado, están todavía en trance de finalizarse, y por tanto surgen constantes dudas, reticencias, abandonos de algunos proyectos e incertidumbres, que dibujan un panorama muy heterogéneo e inseguro.

Las reivindicaciones parcialmente similares expresadas en los movimientos de manifestación ciudadana se han traducido en unos resultados muy divergentes en los distintos países árabes. La inestabilidad se ha adueñado de Libia, de Yemen y de Siria, mientras que los cambios constitucionales y políticos han sido muy profundos en países como Egipto o Túnez. Los ideales democráticos que estaban en el fondo de estos procesos de transformación han triunfado, con un éxito notable, en este último país. Túnez ha escapado del destino de sus vecinos libios, ha conseguido aprobar un texto constitucional en muchos aspectos homologable a los de las democracias europeas y americanas, abriendo el camino para instaurar en su praxis jurídica y política un sistema de libertades que garantice el pluralismo religioso e ideológico. La novísima Constitución Tunecina ha recogido y adaptado las influencias del Derecho europeo, en un esfuerzo por armonizar la cultura jurídica occidental con su propia tradición política y con los contenidos de la legislación islámica. La compatibilidad entre el Islam y los derechos humanos está siendo un monumental logro del sistema constitucional tunecino, que, sin duda, en el futuro constituirá un modelo a seguir por todo el mundo árabe.

Egipto, después de dos procesos constituyentes distanciados unos pocos meses entre sí, sigue en una azarosa incertidumbre. El derrocamiento en el año 2011 del régimen militarista, corrupto hasta lo insoportable y escasamente comprometido en la garantía de los derechos humanos más elementales, de Hosni Mubarak condujo a un inmediato protagonismo de opciones ultrarreligiosas islámicas que habían sido perseguidas por el aparato estatal durante decenios. El sufrimiento padecido por organizaciones como los Hermanos Musulmanes, que habían soportado una represión brutal y despiadada denunciada por toda clase de instituciones internacionales, les otorgó una legitimidad social reforzada a la hora de encauzar la evolución del Estado egipcio tras el derrocamiento de la dictadura. La obra jurídica de estas organizaciones islamistas tuvo su hito nor- 
mativo en la Constitución de 2012, aprobada en referéndum por el pueblo egipcio con un apoyo nada desdeñable. La instauración de una religión de Estado, la islámica, relegando otras opciones, si bien minoritarias también arraigadas en la sociedad egipcia, y la traslación de la ley islámica a todo el ordenamiento jurídico, cuestionaron el carácter plural y auténticamente democrático de este primer intento constitucional.

Las insuficiencias en el amparo y garantía de derechos y libertades presentes en el texto constitucional de 2012 fueron aprovechadas para decretar desde el ejecutivo, en un ambiente de gran turbulencia política, su suspensión. Se inicia un complejo y contradictorio proceso que culmina con la aprobación en referéndum de la actual Constitución de enero 2014, texto que toma como punto de partida el anterior de 2012, pero con intensas reformas en aspectos cruciales para la construcción de un Estado de Derecho digno de tal nombre.

A partir de la aprobación del nuevo texto constitucional, las tensiones entre islamistas y laicistas han sido una constante, ocasionando un ambiente de inestabilidad que, de alguna forma, afecta al resto del mundo árabe, trastornado por actos bélicos en distintos escenarios. La instauración de un régimen garante de derechos y libertades solo puede lograrse, según el criterio dominante de la Comisión de Expertos que redactó el vigente articulado constitucional egipcio, mediante una erradicación del signo de islamización política y jurídica pretendida por la Constitución de 2012.

La Constitución egipcia de 2014 elimina las denominadas cláusulas de identidad, que ofrecían un estatus excesivamente institucionalizado e incluso privilegiado de la religión islámica. La nueva Constitución intenta recuperar el protagonismo de la sociedad civil, empleando para ello un tono que recuerda el racionalismo de los textos europeos aprobados después del triunfo de la Revolución Francesa. El texto que puede construir el futuro de la sociedad egipcia trata de implantar los principios de tolerancia y respeto institucional propios de la Ilustración, consolidando con firmeza un entramado institucional de tutela de los derechos fundamentales y las libertades públicas. De forma contradictoria con los valores de una sociedad plural, la Constitución refuerza el papel político de las fuerzas armadas egipcias, como valedoras del freno al islamismo radical. En esto sentido, el estamento militar mantiene una competencia muy amplia para enjuiciar a civiles ante órganos de su propia justicia.

De espaldas a la realidad social egipcia, desde la Constitución de 2014 se excluye por completo de la vida política a la organización islámica de los Hermanos Musulmanes. Se articulan gravosos impedimentos para el partido de corte salafista Al-Nour, y otras instituciones islámicas como al Al-Azhar también ven recortadas sus posibilidades de actuación política dentro del nuevo marco constitucional. Los movimientos de oposición, incluso violenta, del mundo islamista está ocasionando gravísimos incidentes y tensiones, sin que el Estado de Derecho consiga todavía instaurarse con sólidas perspectivas de futuro. En esta convulsión política y constitucional, para mayor complejidad, los partidarios del defenestra- 
do Presidente Mubarak han alcanzado un renovado ímpetu político. Se ha derogado el artículo 232 de la Constitución de 2012, por el que se establecía un período de reflexión de diez años, durante el cual el partido de Mubarak, el Partido Nacional Democrático, no podía promover a sus líderes para cargos políticos representativos ni para el ejecutivo. La Constitución refuerza el garantismo de derechos y libertades permitiendo una amplia actuación del denominado Tribunal Constitucional Supremo, cuya composición pretende alcanzar un óptimo grado de independencia de todos sus miembros, seleccionados entre las más notables personalidades de la vida jurídica egipcia. La jurisprudencia puede facilitar con su actuación la instauración y consolidación de un Estado social de Derecho, y para conseguir dicho objetivo, deber afrontar varios retos inmediatos: conciliar el Derecho islámico con los valores y principios de un Estado de Derecho propio de nuestros días, facilitar una interpretación de la Constitución valedora de una división de poderes sin excesivas interferencias de las fuerzas armadas, y crear un ambiente jurídico que permita una amplia libertad religiosa e ideológica, en la que puedan ejercer sus derechos constitucionalmente reconocidos tantos las mayorías de religión islámica como las minorías practicantes de otros credos.

La actual Constitución egipcia permite un esfuerzo de interpretación jurídica que vaya más allá de un Islam sin contacto con las mejores tradiciones jurídicas europeas nacidas de las revoluciones británica y francesa. El islamismo jurídico es extraordinariamente plural, y en él pueden despegar con éxito el debate racional y el encuentro en puntos de consenso entre distintas escuelas islámicas. En la más avanzada tradición jurídica islámica, cabe una interpretación de textos normativos de origen sagrado que no desconozca las aportaciones del ordenamiento civil.

Jordania comparte una reciente evolución política bastante similar a la de Argelia y a la de Marruecos. Los fenómenos de protesta popular que han sacudido los países MENA (países Oriente Medio y Norte de África) han sido mucho más débiles y episódicos en el caso jordano. La monarquía jordana, como la marroquí, ha conseguido una gran estabilidad política e institucional, y ello se debe principalmente a sus facultades arbitrales y moderadoras de las distintas fuerzas tribales que influyen netamente en la constitución de la sociedad política jordana. Esta mayor estabilidad ha permitido que, en lugar de derogar el texto constitucional jordano de 1952, se haya procedido a su reforma, con el fin de profundizar en el régimen de libertades y de perfeccionar la Monarquía parlamentaria ya existente. A diferencia de lo sucedido en Egipto con años y años de represión y corrupción ejercidas por el régimen defenestrado por la presión popular, la monarquía hachemita, incluso en los momentos de mayor descontento ciudadano, ha mantenido una alta legitimidad, lo que ha permitido afrontar un camino pausado de reforma constitucional y legal. Ante las protestas sociales, siempre mucho más tenues que las tunecinas, egipcias, sirias o libias, el régimen jordano reaccionó a tiempo con transformaciones legales y constitucionales. Una situación económica bastante saneada ha facilitado este cambio amable y sosegado. Las fuerzas armadas y de 
seguridad han sido, además, muy eficaces a la hora de controlar ciertos fenómenos de islamismo radical que podría resultar altamente desestabilizador.

La monarquía jordana sigue gozando de gran prestigio entre su pueblo. Está arraigada en tradiciones históricas que la sociedad jordana valora y respeta, y asienta con renovada fuerza su actual papel porque permitió en su día el nacimiento del moderno Estado jordano. Incluso antes de la aparición de movimientos de reivindicación popular, el actual monarca Abdulla II accedió a su alta responsabilidad con la premisa de reformar las instituciones jordanas, para conseguir un Estado de Derecho más eficaz a la hora de responder a las exigencias de democracia, justicia, pluralismo y libertad de sus conciudadanos. La monarquía jordana, como sucede con la marroquí, encuentra un criterio de legitimidad, algo extraño para los europeos del siglo XXI, en su carácter claramente religioso, lo que aumenta el margen de maniobra regio a la hora de proponer y fomentar reformas desde cierto paternalismo tutelador de derechos individuales y hasta sociales. El poder del Rey sigue siendo la piedra angular de todo el sistema político, pero con las modificaciones constitucionales acontecidas desde 2012, se intenta un nuevo equilibrio entre las posturas más conservadoras y las más democratizadoras, que permita profundizar en la garantía y ejecución de derechos políticos, sobre todo los que articulan una participación política ciudadana más plena. Las reformas emprendidas por y desde la institución monárquica han servido para afianzar la estabilidad institucional del régimen.

El régimen jordano ha sobrevivido modificando levemente la división de poderes, siempre matizada por las destacadas facultades ejecutivas del monarca, quien incluso influye en la composición de las cámaras legislativas. Esta intervención de la monarquía provoca que distintas instancias internacionales sigan calificando la realidad política de Jordania como autoritaria. El monarca mantiene su protagonismo a la hora de perpetuar, con cambios tenues y a veces algo falaces, una fórmula de convivencia propia de una sociedad muy atomizada, necesitada de poderosas instituciones de cohesión. La monarquía hachemita intenta que el factor religioso no sea motor de radicalismo político, que la integración social se consiga mediante un gran nivel formativo de la población, que el poder inmovilista de algunas instituciones estatales no impida el desarrollo de una avanzada economía social de mercado, y que las formas de participación ciudadana sean paulatinamente más abiertas, plurales y democráticas. La estrategia de supervivencia del régimen supone una democratización limitada, una apertura desde la desconfianza, lo que es motivo de crítica por parte de sectores opositores a esta forma de desarrollo tan cicatero del Estado de Derecho.

Con el inicio de las protestas jordanas en el año 2011, la primera reivindicación promovida por los sectores más combativos se refería a que el ejecutivo surgiera de una decisión popular alcanzada en elecciones libres y transparentes, y no de un acto de designación real. Se entiende que con esta plenitud democrática en el acceso a los más altos poderes del Estado, sería posible la instauración de un sistema de respeto y garantía de derechos y libertades. En un sentido de expan- 
sión democrática, se ha modificado la legislación electoral y de partidos, de modo que los últimos procesos electorales han mejorado la representatividad de los órganos elegidos. Sin embargo el monarca nombra a los setenta y cinco miembros del Senado, Cámara que aprueba, enmienda o rechaza los proyectos de ley remitidos por el Congreso. El rey, además, nombra al presidente de un Tribunal Constitucional compuesto por nueve jueces. Esta nueva institución puede tener gran relevancia en la defensa y amparo de un régimen de libertad, participación y pluralismo. Pero la misma Constitución, al arbitrar tres categorías de órganos jurisdiccionales, otorga gran importancia práctica a la ley islámica, ya que los denominados tribunales religiosos de sharia resuelven según este cuerpo normativo los asuntos de estatuto personal de los ciudadanos musulmanes, mientras que los llamados tribunales eclesiásticos resuelven cuestiones de ley personal de aquellos no integrados en la fe islámica, aplicando para ello criterios religiosos de otras confesiones.

Una vez más, congeniar las profundas tradiciones jurídicas presentes en el islamismo, incluso en el más moderado, se presenta como un reto para progresar en la profundización democrática del Estado jordano y en general, del conjunto de Estados del mundo árabe. De ello también depende el progreso en la integración social, económica y política de la mujer, que en el caso de Jordania goza de unas capacidades de actuación sustancialmente mayores que las vigentes en otros Estados cercanos.

La emergencia del llamado Estado Islámico — con ínfulas de Califato-, como expresión de un islamismo radical, intransigente y extremadamente violento, puede reforzar los procesos constitucionales moderados, como contrapunto a ese modelo bárbaro que contradice la propia ética, de la confesión musulmana tradicional, y su voluntad de confluencia con las formas de un estado constitucional moderado.

Creo que ello es un buen ejemplo de las dificultades de establecer categorías universales para este derecho constitucional de futuro y la necesidad de reglas de tolerancia y reconocimiento del pluralismo jurídico, aunque sin debilitar el valor superior del ser humano.

Sin lugar a dudas también necesitamos un esfuerzo de imaginación para encontrar estas vías de superación y no quedarnos atados a formas arcaicas que son verdaderas ficciones jurídicas inoperantes. Un estimado constitucionalista español escribía que «...la capacidad de la norma constitucional para conformar el proceso real del poder se debilita por la presencia de nuevas realidades no previstas cuando se elaboraron los esquemas sobre cuya falsilla seguimos escribiendo las Constituciones» y cita el papel de los partidos políticos, de los grupos de presión, el impacto de los medios de comunicación masiva, la colaboración entre Estado y sociedad civil para las políticas del Estado de bienestar, etc. Y concluye «...la 
consecuencia es la aparición de un cierto arcaísmo constitucional que sólo el recurso a la imaginación creadora puede salvar» ${ }^{20}$.

Hace veinte años, en el prólogo a la primera edición de un libro mío que entonces tenía un título ligeramente distinto al actual, escribí: «Nos encontramos en el umbral del siglo XXI, del tercer milenio de nuestra civilización. No podemos seguir con esta farsa rococó del miriñaque y el polisón constitucionales cuando lo que necesitamos son las escafandras de astronautas legisladores al servicio de un recobrado protagonismo del ciudadano y del hombre libre» ${ }^{21}$.

Este sigue siendo nuestro desafío en la segunda década del siglo XXI.

$$
* * *
$$

TITLE: Constitutionalism trends in the XXI century: reviews and constitutional innovations

ABSTRACT: Trends in the XXI century constitutionalism are subject to innovations and thus questioning the fundamental concepts crisis once - sovereignty, law, representation - as by the growing appreciation of democracy and human rights and freedoms, identified with the constitutional model. Another common aims to focus on control mechanisms and limits to power. The territorial decentralization and the supranational integration influence this constitutionalism must address the conflict between religion and secularism, while defining new concepts to replace other, obsolete.

RESUMEN: Las tendencias del constitucionalismo en el siglo XXI están sometidas a innovaciones y cuestionamientos tanto por la crisis de conceptos antaño fundamentales — soberanía, ley, representacióncuanto por la valoración creciente de la democracia y los derechos y libertades, identificados con el modelo constitucional. Otra corriente pretende centrarse en los mecanismos de control y límites al poder. La descentralización territorial y la integración supranacional influyen en este constitucionalismo que debe abordar la pugna entre religión y laicismo, a la vez definir nuevos conceptos para sustituir a otros, ya obsoletos.

KEY WORDS: Constitutional trends, effectiveness of law, independent judiciary, fundamental rights, democracy and law, political regimes.

Palabras Clave: Tendencias constitucionales, eficacia del derecho, judicatura independiente, derechos fundamentales, democracia y derecho, regimenes politicos.

FECHA DE RECEPCIÓN: 15.05.2015

FECHA DE ACEPTACIÓN: 29.07.2015

20 Martínez Sospedra, Manuel, Manual de Derecho Constitucional. Parte General, Tirant Lo Blanch, Valencia, 2007, p. 161.

21 Colomer Viadel, Antonio, Constitución, Estado y Democracia en el umbral del siglo xxi, Nomos, Valencia, 1995, p. 23. 
